\title{
An Assessment on the Knowledge of Lung Cancer and Its Predisposing Factors among the Inhabitants of Ngeme, Cameroon
}

\author{
Samuel Nambile Cumber ${ }^{1,2, ~ *, ~ I y a m b e ~ M a r i k e ~ M i r a b e l l e ~}{ }^{2}$, Jackson Jr. Nforbewing Ndenkeh ${ }^{2,3}$, \\ Rosaline Yumumkah Kanjo-Cumber ${ }^{2,4}$, Nina Monju ${ }^{2}$ \\ ${ }^{1}$ Discipline of Public Health Medicine, Department of Nursing \& Public Health, College of Health Sciences, University of Kwazulu-Natal, \\ Durban, South Africa \\ ${ }^{2}$ Under Privileged Children and Women Assistance (UPCAWA-SWEDEN), Buea, Cameroon \\ ${ }^{3}$ Department of Biomedical Sciences, University of Dschang, Dschang, Cameroon \\ ${ }^{4}$ Department of Political Science, University of KwaZulu-Natal, Durban, South Africa
}

Email address:

samuelcumber@yahoo.com (S. N. Cumber)

${ }^{*}$ Corresponding author

\section{To cite this article:}

Samuel Nambile Cumber, Iyambe Marike Mirabelle, Jackson Jr. Nforbewing Ndenkeh, Rosaline Yumumkah Kanjo-Cumber, Nina Monju. An Assessment on the Knowledge of Lung Cancer and Its Predisposing Factors among the Inhabitants of Ngeme, Cameroon. Journal of Cancer Treatment and Research. Vol. 4, No. 3, 2016, pp. 21-26. doi: 10.11648/j.jctr.20160403.11

Received: September 23, 2016; Accepted: October 5, 2016; Published: November 19, 2016

\begin{abstract}
Lung cancer is a big threat to health in the world but many people are still unaware of this fact. The American cancer society has classified lung cancer as the most deadly cancer in both men and women in the world. This study was thus implemented with the objective to assess the knowledge of the inhabitants of Ngeme on lung cancer, its predisposing factors, and its prevention and find out the reason for exposure to some of the risk factors. This study wasa non-experimental quantitative study design and using a convenient sampling method, 40 respondents were included in the study. Data was collected from the above participants using structured questionnaires. The study revealed that most of the respondents were able to define lung cancer but had limited knowledge on the risk factors, signs and symptoms and preventions of lung cancer. Also some of the participants despite knowing the risk factors yet chose to ignore them. We thus recommend that health institutions should carry out a mass health campaign on lung cancer to create awareness on the disease in the community. The population should be informed on the dangers of some of the risk factors and measures found to avoid them as much as possible.
\end{abstract}

Keywords: Assessment, Knowledge, Risk Factors, Lung Cancer, Cameroon

\section{Introduction}

Cancer is emerging as a major health problem globally with over 10 million new cases of cancer and more than 6 million death due to cancer worldwide. According to WHO, (2008) there is a high incidence rate of cancer throughout the world and it may reach about 20 million by $2030[1,2]$. The "epidemic" of lung cancer mortality has been identified as a major health issue confronting both developed and developing countries. In 2000, over one million people died from lung cancer worldwide, $53 \%$ of these deaths occurred in the developed countries the remaining $47 \%$ in the less developed countries [2,3]. Estimates suggest that by 2030 all tobacco-related mortality, including lung cancer, will reach around 10 million deaths per year with the greatest increase from the less developed countries. Tobacco is a major risk factor for lung cancer as well as several other types of cancers thus smoking and occupational exposures to potential carcinogenic compounds are considered major risk factors for lung cancer $[3,4,5]$.

Diet and pre-existent non malignant lung disease also have been associated with the risk of developing lung cancer [2, 
4]. Evidence from studies suggest that national smoking prevention police such as banning smoking in public places, increasing cigarette excise taxes, and educating the public on the harmful effect of cigarette smoking, have positive effects on anti-smoking efforts [3-5]. Other causes may result from the interactive effect of smoking to the environment risk [6]. Environmental causes of lung cancer include exposure to second hand smoke, airborne particulates from urban traffic or fossil fuel combustion [7, 8]. It also includes exposure to ambient metal including zinc, chromium, copper, cadmium, and nickel [9]. Arsenic exposure is a clear risk factor including exposure through contaminated water supplies [3, 7, 10].

In Africa cancer is an emerging problem in public health as according to the international agency of research on cancer (IARC) about 715,000 new cancer cases and 542,000 cancer deaths occurred in Africa 2008. Despite these dead cancers continues to receive low public health priority to Africa largely because of the limited resources and other pressing public health problems $[11,12]$.

In Cameroon cancer has been found to be a public health problem. According to the national cancer control Committee, the total cancer burden in the country has increased from an annual incidence of 12.000 in 2004 to 14.000 in 2010 with prevalence of about 25.000 cases [12]. When we look around we find the population of smokers greatly increasing in our society, no matter how much counselling they have received to enable them to stop this act it goes into deaf ears, studies have shown that even those who do not smoke are affected as they have become passive smokers [10-12]. In Douala, there are so many industries which are situated in the heart of the town where there are many inhabitants. The people are predisposed as a long-term effect of continuous and prolonged exposure to pollutants from industrial pollutants. The prevalence of lung cancer keeps increasing, the reason for this is not clearly known as people are sensitized as to what kind of illness might affect them as a result of exposing their lungs to toxic air and how it can be prevented. Despite the existence of so many health facilities and the health talks given on smoking and environmental air pollution many people still involve in habits which predispose them to lung cancer. Rural communities are not spared from this rather the situation can turn out to be more complicated with indoor exposure to black smoke from three stone firesides in addition to smoking and the already mentioned air pollutants from industries which is the case of the Ngeme community. There is thus the need to find out exactly what a community particularly at risk can provide in terms of knowledge on, risk factors and preventive measures of lung cancer.

This study had as main objective to assess the knowledge of the inhabitants of Ngeme on lung cancer, its pre-disposing factors and its prevention. The specific objectives of the study are as thus:

- To identify individual characteristic of the respondents

- To assess the knowledge of the respondents on the predisposing factor of lung cancer
- To assess the knowledge of the respondents on the preventive methods of lung cancer

- To investigate the reasons for exposure to risk factors of lung cancer

- To find out if the respondents go for lung cancer screening

\section{Materials and Methods}

\subsection{Study Design and Duration}

The study design was quantitative in nature; specifically the non - experimental study was used. This enabled the investigator to assess knowledge on lung cancer, its predisposing factors and its prevention. It was carried out from October 2015 to April 2016.

\subsection{The Study Site}

The investigator chose to carry out the study in Ngeme, a village found in Limbe II Municipality, Fako Division, and Southwest Region of Cameroon. The investigator chose to carry out the study in Ngeme because this site is situated around SONARA which is a petroleum company and they are at risk of being victims of air pollution resulting from the release of waste products in the atmosphere. Ngeme is a village found in Limbe II Municipality. It is bounded to the North by the Buea Mountain, to the South by the Atlantic Ocean, to the West by Bobende village and to the East by Mokindi village. Ngeme is headed by a paramount chief appointed by the mayor of Limbe II Municipality. A good number of features make Ngeme a good recreational environment.

\subsection{Target Group and Sampling Method}

The target population for this study was inhabitants of Ngeme village irrespective of the sex, occupation and level of education. The convenient sampling method was used to select respondents for this study with the sample size fixed at 40 .

\subsection{Data Collection Instruments and Procedure}

A structured questionnaire was used to collect data. The questionnaire comprised of both open and close- ended questions, making up a total of 22 questions. It was divided into three sections namely the individual characteristics, their knowledge on lung cancer and its risk factors and finally their knowledge on the prevention of lung cancer. The validity of the instrument was through a pre-test done in Limbola, neighbouring village which is close to SONARA and has similar characteristics like Ngeme. A total of 10 questionnaires were administered on the 1/03/2016 after which the questionnaire was found to be well understood and there was no reason for modifications. For respondents who were literate, the investigator gave out the questionnaire and gave some explanations; it took the respondents about 10 minutes each to complete a questionnaire. For those who were not literate the investigator made interview while filling in the questionnaire with the respondents' answers for French speaking participants, 
the questions were translated to them by the investigator and the answers were given. Proportions were calculated from the collected data and graphical presentations made.

\subsection{Ethical Considerations}

Respect of human rights is an important element that was taken into consideration in this study. Prior to the administration of the structured questionnaire to the respondents, an authorisation was given by the Director of State Registered Nursing School, Limbe as well as permission being obtained from the Chief of Ngeme. The respondents participated in this study willingly giving their consent after being explained the purpose of the study by the main investigator. The confidentiality of the respondents was assured as the questionnaires had no identifiers like names, addresses, telephone numbers etc thus the data collected could not be traced back to any individual or group of persons. This study most importantly had no prejudice on the participants nor on the community as a whole neither did it have a direct benefit to them thus their willingness of each to participate was genuine.

\section{Results}

\subsection{Demographic Data}

The questionnaires were administered to 40 respondents with possibility to choose more than one answer under some multiple choice questions. About $60 \%$ of these respondents were of the male sex and half of the total respondents falling in the age group between 15 years and 30 years followed by the age group (table 1 below). As concerns the occupation of the respondents we noted that $27.5 \%$ of them were students, followed by technicians and civil servants with $17.5 \%$. There were also farmers, traders as well as unemployed inhabitants all these groups with $12.5 \%$.

Table 1. Distribution of Respondents According to Age.

\begin{tabular}{lll}
\hline Age & Frequency & Percentages \\
\hline $15-30$ years & 20 & $50 \%$ \\
$31-45$ years & 14 & $35 \%$ \\
$46-$ years and above & 6 & $15 \%$ \\
Total & 40 & $100 \%$ \\
\hline
\end{tabular}

\subsection{Knowledge on Lung Cancer and Its Risk Factor}

All the respondents accepted having heard of lung cancer and as shown on table 2 below up to $28.30 \%$ of them had heard about lung cancer from school and $26.42 \%$ from the TV or radio. Table 2 below also shows that out of the 40 respondents some heard about it from more than one place.

Table 2. Place where respondent heard about lung cancer.

\begin{tabular}{lll}
\hline Responses & Frequency & Percentage \\
\hline Hospital & 13 & $24.53 \%$ \\
School & 15 & $28.30 \%$ \\
TV or radio & 14 & $26,42 \%$ \\
Health campaigns & 7 & $13.21 \%$ \\
Books or article & 4 & $7.5 \%$ \\
Total & 53 & $100 \%$ \\
\hline
\end{tabular}

When asked what they understood by lung cancer more than half $(55 \%)$ of the respondents accepted the proposition that it was an abnormal growth of calls in the lungs while the remainder $45 \%$ chose wrong propositions (table 3 ). When asked about the signs of lung cancer a majority of respondents $(37.5 \%)$ chose the response option shortness of breath, $35.42 \%$ chose chest pain and $10.42 \%$ chose weakness. About $8.33 \%$ chose others in which they named; cough, weight loss all of the above which were correct with some respondent know more than one answer. On the other hand, $8.33 \%$ chose vomiting which was wrong. Also as concerns the most vulnerable age groups to lung cancer, $65 \%$ of the respondents chose the age groups above 30 years which was correct.

Table 3. Responds as concerns basic definition of lung cancer.

\begin{tabular}{llll}
\hline Response & Frequency & Percentage & Remark \\
\hline $\begin{array}{l}\text { It is growth of lung cells } \\
\text { It is the growth inflammation of the }\end{array}$ & 6 & $15 \%$ & Wrong \\
$\begin{array}{l}\text { lungs } \\
\text { It is an abnormal growth of cells in }\end{array}$ & 22 & $22.5 \%$ & Wrong \\
the lungs & 3 & $55 \%$ & Correct \\
$\begin{array}{l}\text { It is a supernatural disease } \\
\text { Total }\end{array}$ & 40 & $7.5 \%$ & Wrong \\
\hline
\end{tabular}

As shown on figure 1 below, more than half of these respondents recognised that smoking was a risk factor to lung cancer (with 58.3\%) but failed to recognise that the other propositions like radon gas and lung diseases. On the other $5 \%$ of them accepted that cold was a risk factor to lung cancer. Some of the respondent none the less chose more than one answer.

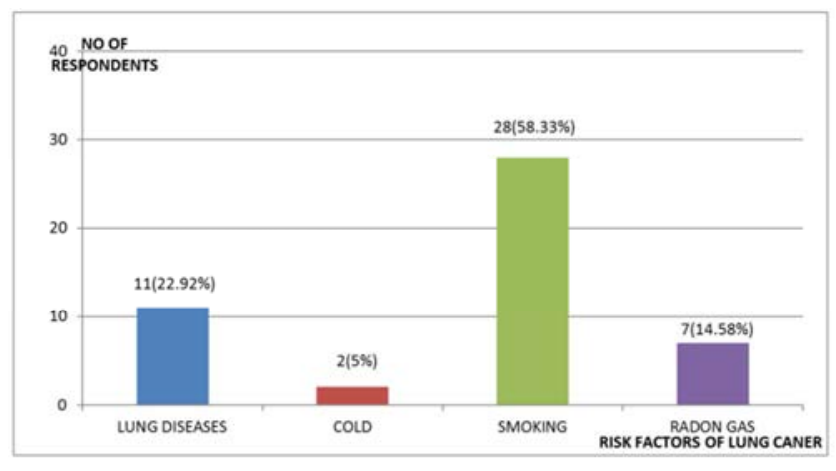

Figure 1. Bar chart showing the distribution of respondents according to risk factors.

Out of the 40 respondents, $77.5 \%$ of them were nonsmokers while $22.5 \%$ were smokers. Also $72.5 \%$ of the respondents accepted when asked about the respondents living or working around another who smokes even though $89.6 \%$ of them were aware that being beside a smoker constantly increases their risk of getting lung cancer. Still out of the 40 respondent $90 \%$ knew that smoking was not good for the health because it could lead to many diseases. However, a small fraction (10\%) of them said they are already addicted to smoking and they cannot stop.

A majority of these respondents $(40 \%)$ were living in Ngeme because they had a family there, others because of 
work, while some were there either as visitors or because of school (15\% and $10 \%$ respectively). Also, $57.5 \%$ of the above respondents accepted knowledge of their living environment constantly being polluted with $87.5 \%$ acknowledging that the polluted air could be a possible risk factor of lung cancer.

\subsection{Knowledge on the Prevention of Lung Cancer}

Out of the 40 participants in this study, $95 \%$ of them had never gone for lung cancer screening and most of them said it was out of negligence, some said they never found the need to go for the screening. For the 5\% who have gone for screening, they said they did it upon doctor's request. When asked about the methods of screening they know the reponses given were as shown on table 4 below.

Table 4. Distribution of methods of screening known by the respondents.

\begin{tabular}{llll}
\hline Responses & Frequency & Percentages & Remark \\
\hline X - ray & 25 & $62.5 \%$ & Correct \\
Biopsy (lab exam) & 13 & $32.5 \%$ & Correct \\
Physical examination & 1 & $2.5 \%$ & Wrong \\
CT - scan & 11 & $27.5 \%$ & Correct \\
Others (specify) & 0 & $0 \%$ & \\
Total & 40 & $100 \%$ & \\
\hline
\end{tabular}

From table 4 above, $62.5 \%$ chose $\mathrm{X}$-ray, $32.5 \%$ chose Biopsy, 11(27.5\%) chose CT scan which were all correct. A small proportion of $2.5 \%$ chose physical examination which is a wrong answer and no respondent knew any other method of screening out of the ones proposed.

As concerns lung cancer prevention mechanisms the responses given by the participants of this study are shown on figure 2 below.

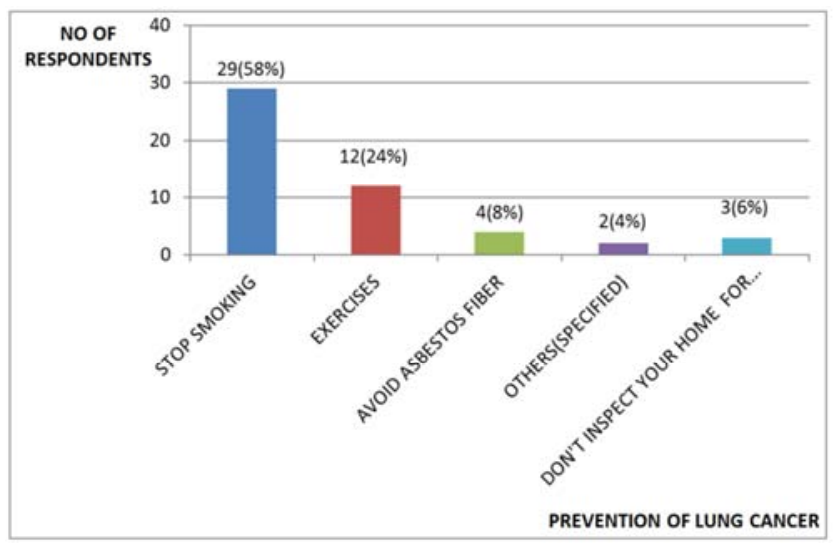

Figure 2. Distribution of response in accordance to how lung cancer can be prevented.

Figure 2 above shows that a majority of $58 \%$ gave 'stop smoking' as a preventive measure which was correct answer, $24 \%$ gave 'exercises', $8 \%$ avoid asbestos fibre and $4 \%$ other prevention (specifying the stop of alcoholism and avoiding second hand smoking) which were correct. A small proportion of $6 \%$ gave 'don't inspect your home from radon gas' which was wrong.

Also only about half of the above respondents accepted that screening was a method of prevention of lung cancer. Reasons for the choice in accepting or rejecting above assertion fell in the following: Some said it was a way to know about your health and know what to do to make it better, others said it does not prevent you from being affected by the disease while the remainder never had a reason for their choice of answer.

\section{Discussion}

This study was implemented to get a picture of the knowledge of the inhabitants of Ngeme community on the lung cancer, its risk factors and prevention. With respect to age group majority of the respondents were between 16 to 30 years and 31 to 45 years and above. As concerning sex, majority of respondent were males as well as being students as concerns occupation.

Most of the respondents had heard of lung cancer from different sources; some in hospitals, others in schools, on television or radio, during health campaigns and others when reading books, articles, a few said they had never heard but still went ahead to answer the other questions. Well may be they were just confused with the term 'lung cancer'. Majority of the respondents were able to define lung cancer as an abnormal growth of cell in the lungs. This is in accordance with the National Cancer Institute (2015), which states that "lung cancer is a malignant lung tumour characterised by uncontrolled cell growth in tissues of the lungs" [11, 13]. The respondents knew one or more predisposing factors of lung cancer as smoking, random gas, lung diseases which is in accordance with the American cancer society (2015), which state that "smoking, random gas and lung diseases are all predisposing factors of lung cancer" $[11,13]$. The real issue here is most of them knew only smoking as a risk factors giving less attention to the exposure factors like radon gas from industrial background which they were rather very exposed to in their community.

Most respondents said they do not smoke. Reasons advanced for not smoking included the fact that it is not good for their health; it is the cause of most respiratory diseases and can affect other systems too. This is in accordance with Nordquist in 2015 who states that "Smoking is responsible for many diseases such as respiratory and heart diseases". Some do not smoke because it is an order given by the doctor not to aggravate their illness [14]. Some of the respondents were smokers, some said they smoke due to peer pressure, others believe it is a solution to their problems. This is in accordance with American Cancer Society in 2015 which states that "Smoking starts in most people due to having friends or parents who smoke, tobacco price breaks and emotional stress" and some said they know smoking is detrimental to their heath but cannot stop smoking no matter how hard they try $[11,13]$. This is in line with Holt who states that "Nicotine addiction not only perpetuates one's desire to smoke but it makes it difficult to apply mind over matter and quit" [9, 13]. Also, the American cancer society states that "smoking is the greatest predisposing factor of 
lung cancer" [11]. Despite not being smokers, a majority of the respondents have someone around them who smokes either living with them or working with them and they are all aware that being around that person is a risk to their health. Those who do not live with smokers were also aware that being around a smoker is a risk to their health. This is supported by the American cancer society which states that "passive smoking is a predisposing factor to lung cancer" $[11,13]$.

Many of the respondents are living in Ngeme because they have a family there or because it is their village. Some because of work, visit or school, and most of them agreed that it is a polluted environment and is detrimental to their health which predisposes them to lung cancer. This is in accordance with Cancer research UK in 2016 which states that " both indoor and outdoor air pollutants have been shown to increase the risk of cancer", a few did not agree the environment is polluted and are aware that polluted air may predispose them to lung cancer. ${ }^{13}$ Some did not know polluted air predisposes them to lung cancer. It is in accordance with the American cancer society which states that "air pollution is a predisposing factor of lung cancer [11]. Most of the respondents are aware that lung cancer is the most deadly of all cancers but some are not aware. This is in accordance with Ferreccio who states that "classified lung cancer is the most deadly cancer for both men and women worldwide [15].

Lung cancer takes a long period to manifest and can start manifesting from 30 years, and above all depending on the age at which the person starts smoking and the quantity the person smokes a day. The frequency at which the person exposes him or herself to the other predisposing factors. This is in accordance with the American cancer society and Richard, which states that "lung cancer occurs in older people $[11,16]$. About 2 out of 3 people diagnosed with lung cancer are 65 or older while less than $2 \%$ are younger 43 the average age of the time of diagnosis is about $70[15,16]$. Majority of the respondents mentioned more than one sign and symptom of lung cancer which are: chest pain, weakness, shortness of breath, a few named some they knew like coughing and weight loss which were correct. This is in accordance with the American cancer society which states that "chest pains, weakness, shortness of breath are signs and symptoms of lung cancer" $[11,13]$ A gave vomiting as a sign and symptoms of lung cancer. Majority of the respondents said they have never gone for lung cancer screening. Most of them said it is because they never found the need to go for the test, others said it was out of negligence, the few who said they have gone for screening said they did so because the doctor asked them to do it.

Most of the respondents know a method of lung cancer screening as x-ray, biopsy (lab exam), CT-scan. This is in accordance with Fong and American cancer society which states that "x-ray, CT-scan and biopsy (lab exam) are methods of screening for lung cancer [11, 17]. A few said physical examinations can be used to diagnose lung cancer which was wrong [17]. Most respondents said lung cancer can be prevented which was right while one said it cannot which was wrong $[17,18]$. Many chose at least one method by which lung cancer can be prevented as stopping smoking, promoting exercises, avoid asbestos fibre and others specified other methods of prevention likestopping alcohol intake and avoid second-hand smoking which were all correct and it is in accordance with the Texas oncology news release in 2016 which states that "exercise, avoid working with asbestos fibre, stopping smoking are all methods of preventing lung cancer" $[11,18]$. Most respondents said screening was a method of prevention which was right and they said it was important to go for screening because it could help for early detection and also help one to improve his health habit to maintain or be in a good health status. A minority did not think it is a method of prevention and had no reason for it which was wrong. This is in accordance with the Texas oncology news release which states that "screening and early detection is a method of prevention [18].

\section{Conclusion}

As conclusion, it was noted generally that the respondents were aware of the disease but had limited knowledge on predisposing risk factors and prevention. It was easy to single out smoking as a risk factor more than the other risk factors like exposure to radon. A good number of these respondents were aware that the environment in which they live was polluted as well as some being aware of the danger of smoking but yet chose to ignore them. There is thus the need to increase knowledge and awareness on lung cancer and other cancers in the community considering the air pollution as a risk factor. This can be done by mass communication for behavioural change by health personnel. The industries should build very high chimneys as well as reduce the use of asbestos fibres. Smoking on the other hand should be completely banned from public places since awareness alone is not making any difference. There is also the need to implement large scale studies in the above domain so as to understand the direct effect of each of the factors on the occurrence of the disease in the local context. Voluntary cancer screening should be vulgarised in the population this accompanied with availability of affordable test kits.

\section{References}

[1] W. H. O (2008). International agency for research on cancer worldwide report.

[2] GLOBOCAN 2000. Cancer incidence, mortality and prevalence word wide IARC cancer base No 5. Version 1.0.1 (online database), lyon international Agency for Research on caner, 2001.

[3] Gandini S, Botteri E, Iodice S, et al (2008). Tobacco smoking and cancer: a meta-analysis. Int $\mathrm{j}$ cancer, 122, 155-64. In AlNaggar A. R, Kadir A. Y. S(2013) Lung cancer knowledge among secondary school male teachers in Malaysia, Asian pacific journal of cancer prevention, vol 14, p 103-104. 
[4] Pride N. B, Soriano J. B (2002). Chronic obstructive pulmonary disease in the united kingdom trends in mortality, morbidity and smoking curropin. In Al-Naggar A.R, Kadir A.Y.S(2013) Lung cancer knowledge among secondary school male teachers in Malaysia, Asian pacific journal of cancer prevention, vol 14, p 103-104.

[5] Wagon G. N, Hecht S. S, Felto J. S, Conney A. H, loeb L. A (2004). Environmental and chemical carcinogenesis. Semin cancer biol, 14, 473-86. In Al-Naggar A.R, Kadir A.Y.S(2013) Lung cancer knowledge among secondary school male teachers in Malaysia, Asian pacific journal of cancer prevention, vol 14, p 103-104.

[6] Boffetta P. (2006) Human cancer from environmental pollutant: the epidemiologicalevidence. Mutat Res; 608:157162.

[7] Sasco A, Secretan M. B, Straif K. Tobacco smoking and cancer: a brief review of the epidemiological evidence. Lung cancer, 45, 3-9. In Al-Naggar A.R, Kadir A.Y.S(2013) Lungcancer knowledge among secondary school male teachers in Malaysia, Asian pacific journal of cancer prevention, vol 14, p 103-104.

[8] Vinieis P, Hock G, Krzyzanozski M, Vigantaglianti F, Veglia F, Airoldi L et al (2007). lung cancer attributable to environmental tobacco smoke and air pollution in nonsmokers in different European countries: a prospective study. Environ health; 6:7. In Hendry M. O'Donnell K. Horn K.(2008) lung cancer mortality is elevated in coal mining areas of Appalachia, Department of community medicine west Virginia university, Virginia. p 2.

[9] Coyley Y. M, Minahjuddin A. T, HynanL. S, Minna J. D.(2006) An ecological study of the association of metal pollutant with lung cancer incidences in Texas. J Thoraconcol; 1:654-661. In Hendry M. O’Donnell K. Horn K. (2008) lung cancer mortality is elevated in coal mining areas of Appalachia, Department of community medicine West Virginia University, Virginia. p 2.
[10] Jones S. R, Qtkin P, Holroyd C, Lutman E, Battle J. V, Walker P. Lung cancer mortality at a UK tin smelter.occup med 2007; 57:238-245. In Hendry M. O'Donnell K. Horn K.(2008) lung cancer mortality is elevated in coal mining areas of Appalachia, Department of community medicine west Virginia university, Virginia. p 2.

[11] American cancer society (2015). Why people smoke and why it's hard to stop smoking. www.cancer.org.

[12] EnowOrock G. E, NdomP, Doh A. S. (2012) Current cancer incidence and trend in Yaoundé, Cameroon, oncolgastroenterol. HepatolRes. 1(1):58-63.

[13] Cancer Research UK (2016). How air pollution can cause cancer.

[14] Nordquist Christian (2015). Why is smoking bad for you? Medical news today.

[15] Ferreccio C, Gonzalez C, Milosavjlevic V, Marshal G, Sancha A. M, Smith A. H. (2000) Lung cancer and arsenic concentration in drinking water in chile. Epidemiol; 11:673679 In Hendry M. O’Donnell K. Horn K.(2008) lung cancer mortality is elevated in coal mining areas of Appalachia, Department of community medicine west Virginia university, Virginia. p 2.

[16] Richard A. Matthay M. D (2002). Clinics in chest medicine lung cancer, 23.In Al-Naggar A. R, Kadir A.Y.S(2013) Lung cancer knowledge among secondary school male teachers in Malaysia, Asian pacific journal of cancer prevention, vol 14, $\mathrm{p}$ 103-104.

[17] Fong K, Brown C, Colburn G, Ball, et al (2014). Diagnosing lung cancer, cancer council or www.cancervic.org.

[18] Texas oncology news releases (2016). Lung cancer screening and prevention or www.texsoncology.com. 